\title{
Los Twindignados: The Rise of the Indignados Movement on Twitter
}

\author{
Narseo Vallina-Rodriguez, Salvatore Scellato, Hamed Haddadi, Carl Forsell, Jon Crowcroft and Cecilia Mascolo \\ The Computer Laboratory, University of Cambridge, UK \\ E-mail: name.lastname@cl.cam.ac.uk
}

\begin{abstract}
Twitter has already become an important facet of the social Web, allowing users and organizations to share their ideas and subscribe to others' updates. Notably, it has been actively used during political events such as the recent elections in Iran, Spain and the USA, or the uprisings in the Middle East, to the extent that it is claimed that revolutions will be tweeted. However such claims are yet to be empirically established.

In this work we study an extensive set of millions of tweets themed around the 2011 regional and local elections in Spain and their accompanying civil unrest. Our analysis shows that mainstream political entities were overshadowed on Twitter by grassroots movements discussing alternative points of view, at both regional and national levels. By tracking temporal trends we discover an explosion of interest in the Spanish protests following the establishment of the first protest camps in Madrid. The subsequent spontaneous setting up of similar camps in almost every town in Spain was widely reported at the time, and our spatial analysis quantitatively attests that the protests were indeed widely discussed in all parts of the country. Our results suggest that online social networks serve more as media for interactive engagement between grassroots peers, rather than as platforms for politicians to attract mass attention.
\end{abstract}

\section{INTRODUCTION}

Since 2008 Spain, like many other European countries, has been experiencing a severe financial and political crisis. A survey [1] conducted in early May 2011 found that the Spanish population was overwhelmingly concerned with unemployment, the economic situation and the party political system; all other issues were insignificant in comparison.

In this precarious context Spain prepared for the regional and local elections of 22 May 2011, a long-awaited barometer of public opinion toward the positions taken by the main political parties since the start of the crisis, and a portender of the outcome of November's national elections.

\section{A. The Spanish Revolution}

From early on, the debate over the political crisis moved onto blogs and online social network services. Spanish cyberactivists used these tools to gain adherents and to protest against the prevailing situation. This discussion gave birth to the collective ;Democracia real, Ya! (DRY; in English: "Real democracy, Now!") inspired by Hessel's essay “Indignezvous!" [2] and by the recent events of the Arab Spring.

Members of DRY called for public demonstrations to be held on 15 May in more than fifty cities across Spain. These evolved into what was later referred to as the "Spanish Revolution”, with protesters spontaneously setting up camps in many of the cities. Once again, activists in these camps used Twitter as a channel for discussing their position and organizing themselves. A broad movement was born, whose members call themselves "los indignados" ("The Indignant"), taking their name from the title of Hessel's polemic text.

\section{B. Twitter and "los indignados"; our contributions}

Twitter and Facebook were the main communication platforms for spreading the messages put forward by the protesters. On Twitter, it did not take long for a set of hashtags to become widely adopted for discussing the political issues at stake and engaging with the protesters. As camps sprang up in many Spanish cities and across Europe, the use of Twitter to mobilize and comment on the protests became widespread.

In this paper, we present our study of the way Twitter was used during these events, in Spain and elsewhere. We analyse a dataset comprising more than 3 million tweets collected over more than two weeks, obtained by tracking a set of key hashtags and users. We shed light on the electoral, political and social debate that took place on Twitter about the regional and local elections of May 2011 and the early days of the Spanish revolution, which would directly inspire the worldwide cascade of Occupy protests of the latter half of the year. The findings of our analysis are fourfold:

- We found that the majority of the election-related tweets expressed an alternative political orientation outside the traditional left-right political spectrum.

- Our analysis showed that mainstream political activity on Twitter was overshadowed by that of alternative forces.

- We observed that Twitter activity closely followed over time the events of the protests, in particular displaying an explosion of interest with the establishment of the first protest camps.

- We analyse where tweets were sent from in order to grasp the spatial properties of Twitter activity, and found that the protest movement was far from being a localized phenomenon, although Madrid clearly remained the centre.

\section{Related work}

With more than 120 million tweets sent every day, Twitter traffic constitutes a vast corpus that can be useful for shedding light on many socio-political questions which need interaction data from large numbers of people. In particular, Twitter data have been used to validate theories of social influence [3], and it has been claimed that sentiment analysis and counting of tweets can be used to predict the outcomes of elections [4]; 
this interest has inspired more general efforts to investigate the landscape of political inclinations on Twitter [5], as well as Twitter's effects on the external political landscape during protests such as those following the 2009 Iranian presidential election [6]. In the cases of Iran or the revolts of the Arab Spring, national telecoms operators' attempted bans on social media severely restricted the use of these networks in the coordination of protests. The situation surrounding the Spanish elections was different, and of interest, in the sense that individuals there were freely using Twitter to organize protests.

Doubts have been cast on the claims made in [4] and subsequently, of the effectiveness of Twitter as a predictor of election results; an exhaustive (and highly skeptical) survey of this research sub-field can be found in [7]. Although psephology is not one of our concerns in this paper, it could be argued that our results corroborate the skeptics' case.

Focusing on the 15 May movement, González-Bailón et al. [8] used structural criteria to study protest recruitment patterns in the Twitter network and look for evidence of social influence and complex contagion. They found that early participants cannot be characterized by topological position, but that spreaders tended to be more central in the network.

\section{ECONOMIC AND POLITICAL CONTEXT}

In May 2011, 13 out of the 17 Spanish autonomous areas were facing regional elections. Moreover, more than 8000 municipalities were having local elections at the same time.

\section{A. The Spanish political spectrum}

Spain's political spectrum is diverse. More than 100 parties participated in the regional elections alone. There are however two dominant political parties: $\mathrm{PSOE}^{1}$ and $\mathrm{PP}^{2}$. Nationalist parties have a notorious presence in some regions and along with regionalist parties constitute a significant electoral force decisive in the forming of coalition governments.

\section{B. Timeline of events}

A month before the elections, the government announced unprecedentedly high unemployment statistics, of over $20 \%$ of the active population. Opposition media groups and political parties claimed that the PSOE government was responsible, pointing to its slow early efforts at tackling the crisis. However, public criticism also targeted the PP for having members who were involved in ongoing corruption cases. The debate moved to the Internet, where even as early as February there were an estimated more than 20,000 posts per hour.

The platform "Democracia Real, Ya!" was the result of merging more than 200 smaller citizen grassroots organizations, student organizations and other civil movements in early $2011^{3}$. They used a variety of hashtags to promote their actions, some of the most popular of which are described in Table I.

\footnotetext{
${ }^{1}$ Spanish Socialist Workers' Party; social democratic, and in control of the national parliament until November 2011.

${ }^{2}$ People's Party; conservative, largest opposition party in May 2011, and currently in power nationally as well as in most regions.

${ }^{3} \mathrm{http}: / /$ www.democraciarealya.es
}

\begin{tabular}{|c|c|}
\hline Hashtag & Description \\
\hline \hline \#democraciarealya & Official DRY platform hashtag \\
\hline \#Nolesvotes & Do not vote for them (i.e. PP or PSOE) \\
\hline \#Novotes & Do not vote \\
\hline \#15M & 15th of May protests \\
\hline \#spanishrevolution & Comprises all the spanish protests \\
\hline \#acampadasol & Related to Madrid's camp/protests \\
\hline \#acampadabcn & Related to Barcelona's camp/protests \\
\hline \#nonosvamos & We are not leaving \\
\hline \#notenemosmiedo & We have no fear \\
\hline \#nonosrepresentan & They [politicians] do not represent us \\
\hline
\end{tabular}

TABLE I: Description of the most popular hashtags related to the $15 \mathrm{M}$ movement.

On 6 May, the election campaign started; it was the first in which most of the parties had a significant presence on social networks. The main hashtag assembling tweets relating to the elections was \#22M. It was at this time that we started crawling Twitter by monitoring all the regional and national candidates, their campaigns, and everything surrounding the DRY platform.

DRY organized a protest march in more than fifty cities across Spain on 15 May. The protests in Madrid finished at dawn on 16 May, when 19 activists were arrested. Later that day, 10,000 people protested this and started a permanent camp in the popular downtown square Plaza del Sol. They organized assemblies and the hashtag \#acampadasol was used to discuss whatever was happening there. DRY compiled the ideas collected by activists in these small assemblies and published a manifesto of the movement online.

This can be considered the beginning of the \#spanishrevolution, an event that has been compared by some to May 1968, and in post-2008 Europe comparable in scale and significance to the Greek and Icelandic revolts. Other Spanish cities replicated the action, and even Spanish citizens living abroad protested in front of their embassies. But although the Spanish media later dubbed this one of the events of the year, they did not pay much attention to it at the outset, while the main political parties were mostly either critical or lukewarm.

\section{The electoral results}

The PP was the clear winner in the elections, gaining outright majorities in 8 out of 13 autonomies. Spanish voters punished the PSOE and it lost $7.8 \%$ of its 2007 vote share. However, the share of the PP grew only $1.9 \%$ whereas the alternative vote (as expressed in e.g. \#nolesvotes) increased by $5 \%$ on average across Spain. In Madrid and Valencia, the total number of PP and PSOE votes decreased by $10 \%$. This outcome was not anticipated by any of the forecasts of early May; the \#15M movement and the surrounding social disenchantment seem to have been the main causes.

\section{Aftermath}

After the elections, the camps lasted until 13 June in Madrid, and protests also continued elsewhere; 27 May saw one in Barcelona violently suppressed by the Catalan autonomous police. Many public intellectuals considered this protest movement to be what finally ended the two-party system in Spain. 
Various surveys in November 2011 found that the protests were supported by more than $60 \%$ of the Spanish population. In the following national elections, the Socialist party lost power after obtaining its worst results since the reintroduction of democracy in 1978.

\section{DATA COLLECTION}

\section{A. Methodology}

The essential intent of our data collection methodology was to capture a large number of tweets relating to the elections and the political debate surrounding them. Obviously, such a general task is both daunting and underspecified: analysing each tweet shared on Twitter entails examining a large volume of messages (more than 120 million per day), while deciding whether a tweet is related to the electoral discussion can be extremely difficult, due to the semantic subtleties of human language. Thus, we hand-crafted a list of hashtags related to the political discussion and a list of Twitter accounts used by different regional candidates, political parties, the DRY movement and main media sources, together with other social and political keywords. The list of tracked hashtags and accounts was extended in time as the events evolved. In the cases of the four autonomies where regional elections were not being held, we targeted the local candidates of their most populous cities. In total, we tracked more than 200 Twitter accounts and 400 hashtags and terms. Nevertheless, this did not include all candidates and parties since not all had a presence on Twitter. Small parties generally seemed to prefer blogs.

In order to obtain a sanity check for our selection of hashtags and accounts to track, we solicited the views of the parties, organizations and individuals therein. Unfortunately, we received very few replies.

Using Twitter's Streaming API we collected all tweets that either contained one hashtag in our list, mentioned one account in our list or was published by one of the accounts. The data were collected between 10 and 24 May 2011, and we were able to capture more than 3 million tweets sent by about 500,000 Twitter users. These tweets contain more than 115,000 different hashtags.

\section{B. Dataset description}

A large fraction of the users in our dataset sent only a few tweets containing the hashtags on our watch list, or mentioning the users we were tracking: in fact, about $30 \%$ of them sent only one tweet in our sample, as reported in Figure 1a. Moreover, the entire probability distribution is heavy tailed, with a few user accounts contributing hundreds of tweets. An even more uneven distribution is obtained for the number of mentions received by each account in our dataset: as shown in Figure 1b, there is another heavy tail, with the majority of accounts receiving one or no mentions but some receiving above 100,000 mentions.

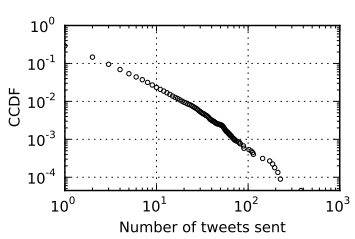

(a)

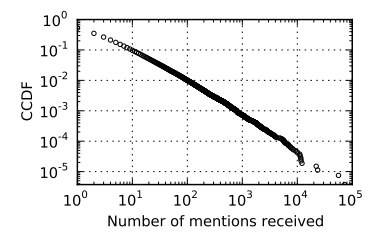

(b)

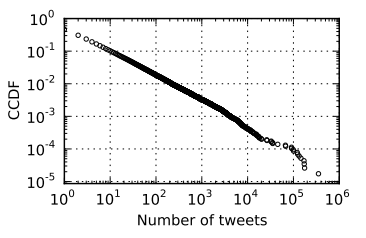

(c)
Fig. 1: Complementary Cumulative Distribution Function (CCDF) of the number of tweets sent by each Twitter user account in our dataset (a), number of mentions received by each Twitter user account (b) and number of tweets which contain a given hashtag (c).

\section{Hashtags}

The tweets in our sample included some noise: even though the hashtags were used mainly to refer to political, social and economic issues, not all were thus employed. For instance, tweets about topics such as football were captured as a consequence of monitoring hashtags such as \#Madrid and \#Barcelona. In Figure 1c we present the probability distribution of the number of tweets containing a hashtag in our list. The popularity of hashtags varies greatly: while the few most-used hashtags appeared in more than 600,000 tweets, thousands were used only a few times. We can see that even though the political debate on Twitter touched a multitude of users and many themes, a small number of these were hugely predominant.

We classify the hashtags along three dimensions: topic, geographic scope and political scope. The topics are assigned according to how each hashtag relates to the elections, protests or any other relevant event that happened during the collection period. Table II gives a few examples of how some popular hashtags of our dataset were classified.

We note how a large number of tweets contain hashtags related to regional and national issues, and that $15 \mathrm{M}$ and DRY were the dominant topics of election-related discussion in Spain during May. Our findings suggest that the majority of election-related tweets expressed an alternative political orientation outside the traditional left-right political spectrum, and most often were concerned with the protest movement or universalist issues such as the electoral process, the economic situation or unemployment rather than single-issue or identity politics. In Table III we present a breakdown of tweets based on such a classification: we compute the fraction of all the hashtags falling into each category as well as a weighted fraction which takes into account how often each hashtag was used. These results confirm that the main debate on Twitter was centred around the alternative politics proposed by the DRY movement and the protesters in the different regions of Spain. 


\begin{tabular}{|c|c|c|c|c|c|}
\hline Rank & Hashtag & Tweets. & Political scope & Geographic scope & Topic \\
\hline \hline 1 & \#acampadasol & 716,434 & Alternative & Regional & DRY \\
2 & \#spanishrevolution & 642,149 & Alternative & National & DRY \\
3 & \#acampadabcn & 352,088 & Alternative & Regional & DRY \\
4 & \#nonosvamos & 175,127 & Alternative & National & DRY \\
5 & \#nolesvotes & 172,093 & Alternative & National & Elections \\
7 & \#democraciarealya & 145,765 & Alternative & National & DRY \\
10 & \#15M & 120,689 & Alternative & National & DRY \\
14 & \#22M & 90,808 & None & National & Elections \\
20 & \#PP & 32,820 & Right & National & Politics \\
22 & \#economia & 26,491 & None & National & Economy \\
28 & \#PSOE & 17,609 & Left & National & Politics \\
35 & \#Bildu & 13,755 & Left & Regional & Politics \\
80 & \#educacion & 6,066 & None & National & Society \\
\hline
\end{tabular}

TABLE II: Some of the most significant hashtags included in our dataset and their classification according to political scope, geographic scope and topic.

\begin{tabular}{|c|c|c|c|}
\hline \multicolumn{2}{|c|}{ Regional scope } & \multicolumn{2}{c|}{ Weighted regional scope } \\
\hline None & $14.20 \%$ & None & $3.17 \%$ \\
Regional & $32.72 \%$ & Regional & $43.06 \%$ \\
National & $37.65 \%$ & National & $46.03 \%$ \\
International & $15.43 \%$ & International & $7.74 \%$ \\
\hline \multicolumn{2}{|c|}{ Political scope } & Weighted political scope \\
\hline None & $41.98 \%$ & None & $26.93 \%$ \\
Left & $5.86 \%$ & Left & $2.25 \%$ \\
Right & $5.86 \%$ & Right & $2.26 \%$ \\
Alternative & $46.30 \%$ & Alternative & $68.56 \%$ \\
\hline
\end{tabular}

TABLE III: Distribution of the top 300 hashtags according to their political and regional scope. Weighted distributions take into account the number of times a hashtag was used.

\begin{tabular}{|l|l|l|}
\hline Region & \# of Users & Percentage \\
\hline \hline Total Spain & 118,492 & 24.08 \\
Madrid & $25,477(3.94)$ & 5.18 \\
Catalonia & $25,107(3.34)$ & 5.10 \\
Andalusia & $14,164(1.68)$ & 2.88 \\
Valencia & $8,519(1.67)$ & 1.73 \\
Galicia & $4,959(1.77)$ & 1.01 \\
Castille and Leon & $4,400(1.72)$ & 0.89 \\
Basque Country & $4,207(1.93)$ & 0.86 \\
Asturias & $3,153(2.91)$ & 0.64 \\
Canary Islands & $2,800(1.32)$ & 0.57 \\
Castille La Mancha & $2,800(1.34)$ & 0.57 \\
Aragon & $2,537(1.89)$ & 0.52 \\
Murcia & $2,496(1.71)$ & 0.51 \\
Balearic Islands & $1,884(1.70)$ & 0.38 \\
Extremadura & $1,679(1.52)$ & 0.34 \\
Cantabria & $875(1.48)$ & 0.18 \\
Navarra & $692(1.09)$ & 0.14 \\
La Rioja & $500(1.55)$ & 0.10 \\
\hline \hline Rest of the world & 149,771 & 30.44 \\
\hline Not Reported & 114,725 & 23.32 \\
\hline Unknown or unreal & 109,064 & 22.16 \\
\hline
\end{tabular}

TABLE IV: Geographic distribution of user accounts present in our dataset. In brackets, the approximate number of accounts per 1,000 inhabitants calculated using Spanish census data from 2001.

\section{Accounts}

Based on the information available on users' profiles, we identified more than 150 countries and a diversity of languages, as can be seen in Table IV. $48.7 \%$ and $46.4 \%$ of all user accounts in our dataset give English and Spanish respectively as main languages. We mapped location data available from user profiles to Spanish regions and interna-

\begin{tabular}{|c|c|c|c|}
\hline \multicolumn{2}{|c|}{ User Type } & \multicolumn{2}{|c|}{ Weighted user type } \\
\hline Politics & $13.53 \%$ & Politics & $15.07 \%$ \\
\hline Media & $34.12 \%$ & Media & $24.80 \%$ \\
\hline 15M-related & $10.59 \%$ & 15M-related & $33.17 \%$ \\
\hline Elections & $3.53 \%$ & Elections & $2.87 \%$ \\
\hline Individuals & $38.24 \%$ & Individuals & $24.09 \%$ \\
\hline \multicolumn{2}{|c|}{ Political scope } & \multicolumn{2}{|c|}{ Weighted political scope } \\
\hline None & $27.57 \%$ & None & $43.53 \%$ \\
\hline Left & $13.51 \%$ & Left & $14.71 \%$ \\
\hline Right & $10.45 \%$ & Right & $10.59 \%$ \\
\hline Alternative & $48.48 \%$ & Alternative & $31.18 \%$ \\
\hline
\end{tabular}

TABLE V: Distribution of all user accounts with more than 1,000 mentions according to their type and political scope. Weighted versions take into account the number of times each user was mentioned.

tional political entities; it was found that $23.32 \%$ of profiles did not have any location information and $22.16 \%$ had misleading or nonsensical location data. Furthermore, $2.59 \%$ of user accounts specified Spain as their location instead of a region or a city. As was expected, accounts located in Madrid or Catalonia were the most numerous, with about $5 \%$ in each region. As some terms such as \#DRY can be shared across different languages, we also gathered a significant number of user accounts located in Brazil (8.06\%), Indonesia (6.13\%), Mexico (2.18\%) and the USA (2.14\%). We filtered out these tweets accordingly.

Similarly to what was done for hashtags, we performed a bidimensional classification for all accounts with more than 1,000 mentions. In addition to their ideology, we took into account their profession, affiliation or the organization they belonged to, obtaining four categories: political parties, the elections, media, the DRY movement and individuals. Their political scope was obtained from their Twitter profile or from their official website.

The user names classification and ranking are similar to those for hashtags, and examples are given in Tables V and VI. However, the distribution according to ideology is more level than that seen in hashtags. This could imply that user popularity is not correlated with the popularity of events [3]. The variation in the number of mentions is moreover not as large as it was for hashtags. This might be because people prefer to use hashtags to mark their own tweets rather than to retweet other users'. 


\begin{tabular}{|l|l|l|l|l|}
\hline Rank & User accounts & \#Mentions & Pol. Scope & Topic \\
\hline \hline 1 & acampadasol & 72,382 & Alternative & DRY \\
2 & acampadabcn & 56,142 & Alternative & DRY \\
3 & democraciareal & 23,494 & Alternative & DRY \\
4 & PSOE & 22,080 & Left & Politics \\
5 & PPopular & 12,194 & Right & Politics \\
6 & el_pais & 11,744 & Left & Media \\
\hline
\end{tabular}

TABLE VI: Most mentioned user names.
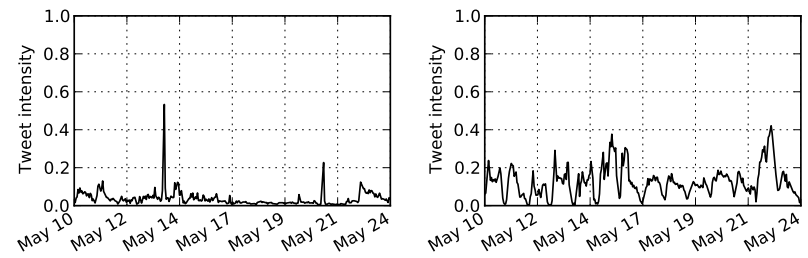

(a) Political Parties

(b) Regional and municipal elections

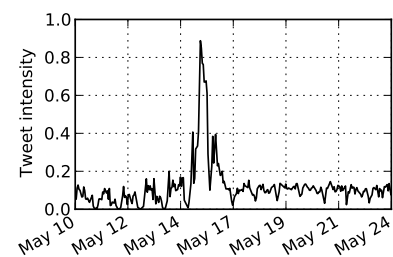

(c) DRY movement

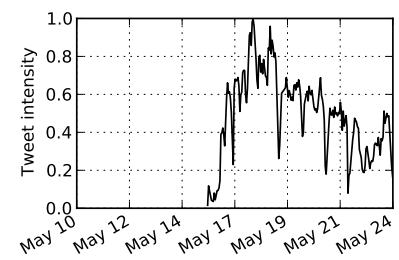

(d) DRY camps

Fig. 2: Temporal evolution of the popularity of the top 5 hashtags in each category. On the y-axis we plot the tweet intensity, i.e. the ratio between the number of mentions and the total number of collected tweets in each hour.

\section{ANALYSis}

In this section we will discuss some temporal and spatial characteristics of the \#democraciarealya movement as it evolved.

\section{A. Temporal context}

The DRY movement on Twitter was consciously coordinated with the protests that were taking place in the streets. To obtain a quantitative picture of this synchronism, we devised four categories of event-topics - political parties, elections, the DRY movement, and the camps - and noted the top hashtags in each; these are displayed in Table VII. Figure 2 shows the number of tweets over time containing each category of hashtag. We focused our analysis on the period between 10 and 24 May. Within this interval it is possible to identify two periods of maximum tweet intensity, corresponding to two key events: the 15 May protests organized by DRY, and the elections on 22 May.

As shown in Figures $2 a$ and $2 b$, the hashtags associated with political parties and the elections remained active and relatively constant in popularity during most of the campaign. However, these categories show a slight increase in activity around the time that the protests broke out on 15 May. This was due in part to users linking the parties with hashtags such as \#nolesvotes in an attempt to make an impact on followers of the two main parties.

On 15 May, hashtags related to \#democraciarealya dominated election-related discussion on Twitter reaching an in-

\begin{tabular}{|l|l|l|l|}
\hline \multicolumn{2}{|c|}{ Elections } & \multicolumn{2}{c|}{ Political parties } \\
\hline Hashtag & Freq & Hashtag & Freq \\
\hline \#nolesvotes & 172,093 & \#pp & 32,820 \\
\#22m & 90,808 & \#upyd & 17,823 \\
\#estoesreflexion & 35,207 & \#psoe & 17,609 \\
\#yovoto & 16,525 & \#bildu & 13,755 \\
\#votoutil & 15,721 & \#votapp & 8,784 \\
\hline \hline \multicolumn{2}{|c|}{ DRY Movement } & \multicolumn{2}{c|}{ DRY Camps } \\
\hline Hashtag & Freq & Hashtag & Freq \\
\hline \#democraciarealya & 145,765 & \#acampadasol & 716,434 \\
\#15m & 120,689 & \#acampadabcn & 352,088 \\
\#15mani & 26,129 & \#nonosvamos & 175,127 \\
\#confloresalas7 & 12,778 & \#yeswecamp & 91,328 \\
\#tomalaplaza & 7,725 & \#notenemosmiedo & 66,848 \\
\hline
\end{tabular}

TABLE VII: The most popular hashtags in each category. Although the camps are part of the DRY movement, they have here been assigned to their own category.

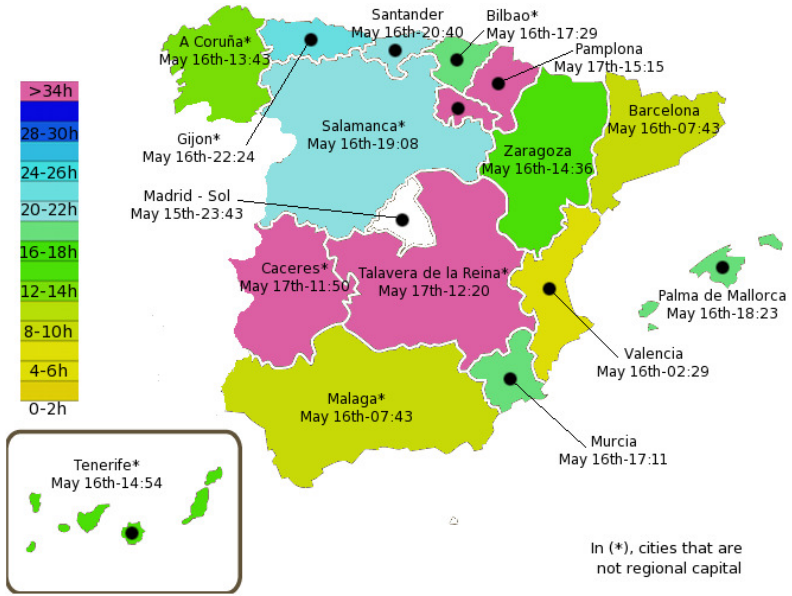

Fig. 3: Times when the regional camps were first mentioned.

tensity of over 0.8 . However, these hashtags began to lose their pull as the camps started to appear all over Spain on the eve of 16 May as shown in Figure 2d. The DRY movement assumed a new form and the camp hashtags picked up the baton from DRY ones. This corroborates the results, already claimed in Section II, that Twitter was dominated by grassroots movements mobilized around the DRY organisation, largely overshadowing official candidates, media and parties.

The parties regained some weak attention as the election results came in on the evening of 22 May, but this lasted little more than a few days: the camps on the other hand remained popular, mentioned in more than $30 \%$ of all tweets.

\section{B. The dissemination of the camps}

Although the DRY movement was a mostly latent force until the days immediately preceding 15 May, hashtags related to it were found to be included in more than $70 \%$ of tweets collected on the day itself. This exemplifies our claim that the pattern of Twitter activity closely followed the timeline of Spanish events described in Section II, with an explosion of interest during the establishment of the first protest camps in Madrid, and subsequently others across the country.

After the protests, people remained in the Plaza del Sol in Madrid until dawn, setting up a permanent camp despite police pressure. The first tweet reporting this camp came at 


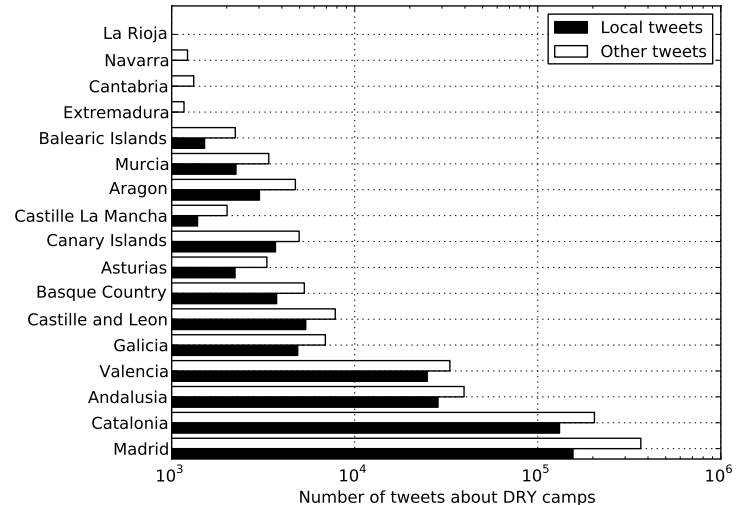

Fig. 4: Aggregated number of tweets about camps located in each Spanish region: tweets generated within each region and in other regions are compared.

around 11:30 p.m. on 15 May. Similar actions followed soon after in other regions of Spain, and were likewise reported immediately on Twitter, at the times given in Figure 3, following which tweets mentioning them went viral, as strongly suggested by Figure 2d.

\section{Inter-regional interactions.}

As shown in Figure 4, most of the tweets about camps referred to those of Madrid, Catalonia, Andalusia and Valencia. A significant amount of cross-mentioning between regions could be seen: most of the camp-related tweets for a given region were sent by users from other regions.

In fact, if one takes into account the number of tweets containing hashtags or mentions referring to any camp at all, it can be seen that Madrid and Barcelona tended to get mentioned at a ratio roughly independent of author location.

Moreover, as can be seen in Figure 5, regional users tended to mention Madrid and Barcelona more than their respective regional camps. However, the tweets generated in Madrid, Barcelona and Valencia were centred mainly on their authors' local camps, as shown in Figure 5a. On the other hand, the level of tweets from other regions mentioning Madrid was high, and is closely correlated with the time it took for local camps to first appear, as can be seen by comparison with Figure 3. To conclude, the protest movements were far from being a localized phenomenon, although their main centre clearly remained Madrid.

\section{Discussions AND CONCLUSIONS}

In this work we have presented a detailed analysis of how Twitter was used in Spain during the rise of the Indignados Movement in May 2011. We analysed a corpus of about 3 million tweets sent by 500,000 different Twitter users, discussing how popular hashtags and key user accounts were driving the discourse around the protest and the political events. We found that grassroots' movements dominated Twitter, overshadowing mainstream political entities. By tracking temporal trends, we found how activity exploded when the protest camps were established in Madrid. Then, our spatial analysis showed that

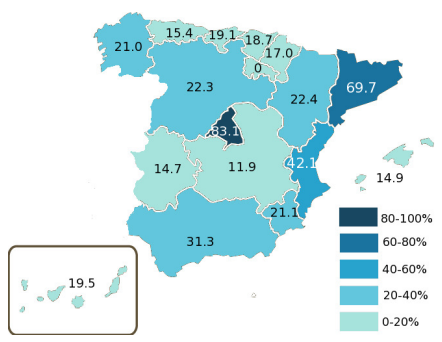

(a) Tweets referring to local camps

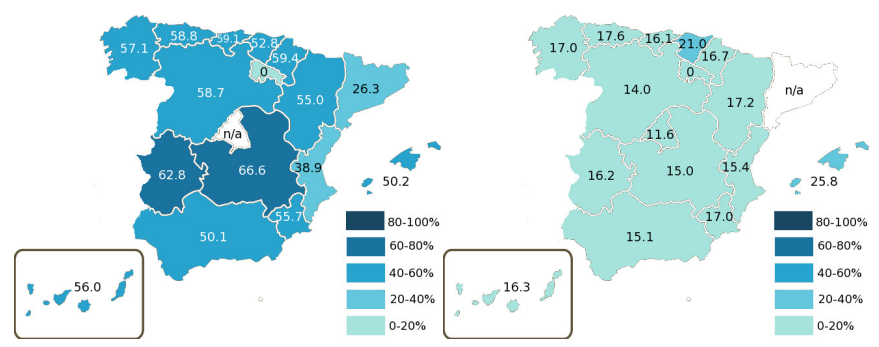

(b) Tweets referring to Madrid

(c) Tweets referring to Catalonia

Fig. 5: Tweets about local camps and tweets referring to the camps in Madrid and Catalonia.

the camps were not a localized phenomenon, and exposed a pattern of regional interaction within the protest movement.

These findings pave the way for exciting future work. We plan to study the evolution of the social network among users, and use our observations to assess the applicability of network models of collective action such as [9].

Our results support the idea that Twitter was heavily used by grassroots movements, likely helping them to share and promote a message of social change. Indeed, it seems to us, the revolution was tweeted.

\section{REFERENCES}

[1] CIS, "Barómetro de mayo de 2011," Madrid: Centro de Investigaciones Sociólogicas, Estudio no. 2888, May 2011. [Online]. Available: http://www.cis.es/cis/export/sites/default/-Archivos/ Marginales/2880_2899/2888/Es2888.pdf

[2] S. Hessel, Time for Outrage: Indignez-vous! London: Charles Glass Books, 2011, translated by M. Duvert.

[3] M. Cha, H. Haddadi, F. Benevenuto, and K. Gummadi, "Measuring user influence in twitter: The million follower fallacy," Proceedings of ICWSM 2010, 2010.

[4] A. Tumasjan, T. O. Sprenger, P. G. Sandner, and I. M. Welpe, "Predicting elections with twitter: What 140 characters reveal about political sentiment," in Proceedings of ICWSM 2010, 2010, pp. 178-185.

[5] J. An, M. Cha, K. Gummadi, and J. Crowcroft, "Media landscape in Twitter: A world of new conventions and political diversity," in Proceedings of ICWSM 2011. AAAI, Jul. 2011. [Online]. Available: http://www.aaai.org/ocs/index.php/ICWSM/ICWSM11/paper/view/2825

[6] L. Grossman, "Iran protests: Twitter, the medium of the movement," Time Magazine, vol. 17, 2009. [Online]. Available: http://www.time. com/time/world/article/0,8599,1905125,00.html

[7] D. Gayo-Avello, "I Wanted to Predict Elections with Twitter and all I got was this Lousy Paper' - A Balanced Survey on Election Prediction using Twitter Data," eprint arXiv:1204.6441v1, 2012. [Online]. Available: http://arxiv.org/abs/1204.6441v1

[8] S. González-Bailón, J. Borge-Holthoefer, A. Rivero, and Y. Moreno, "The Dynamics of Protest Recruitment through an Online Network," Scientific Reports, vol. 1, Dec. 2011. [Online]. Available: http: //www.nature.com/srep/2011/111215/srep00197/full/srep00197.html

[9] M. S. Y. Chwe, "Structure and strategy in collective action," American Journal of Sociology, vol. 105, no. 1, pp. 128-156, 1999. 